\section{Haemodynamic responses to tracheal intubation following etomidate and fentanyl for anaesthetic induction}

The haemodynamic response to anaesthetic induction and tracheal intubation was studied in 29 patients undergoing elective myocardial revascularization surgery. All patients included in the study were anaesthetized with etomidate, 0.3 $\mathrm{mg} \cdot \mathrm{kg}^{-1}$. The patients were randomized to three groups: Group I received fentanyl, $2.5 \mu \mathrm{g} \cdot \mathrm{kg}^{-1}$; Group II received fentanyl, 5 $\mu \mathrm{g} \cdot \mathrm{kg}^{-1}$; and Group III received fentanyl, $10 \mu \mathrm{g} \cdot \mathrm{kg}^{-1}$. Haemodynamic variables were measured at baseline (awake), after anaesthetic induction, and at one, three, five, and ten minutes after tracheal intubation. The number of patients with haemodynamic responses to intubation $(>20 \%$ increase in heart rate or mean arterial pressure) was greater $(P<0.05)$ in Group I than in Groups II and III. Statistically significant, but clinically minor, decreases in mean arterial pressure and cardiac output occurred in all groups at the last three study times. The frequency of involuntary muscle movements was $14 \%$, and all of these events occurred in patients in Group I. In conclusion, the authors recommend using fentanyl, 5-10 $\mu \mathrm{g} \cdot \mathrm{kg}^{-1}$ to blunt the haemodynamic response to tracheal intubation following anaesthetic induction with etomidate, $0.3 \mathrm{mg} \cdot \mathrm{kg}^{-1}$.

Chez 29 patients programmés pour une revascularisation chirurgicale du myocarde, on évalue la réponse hémodynamique provoquée par l'induction de l'anesthésie et de l'intubation endotrachéale. Tous les patients inclus dans l'étude sont anesthésiés à l'étomidate $0,3 \mathrm{~m} \cdot \mathrm{kg}^{-1}$. Par randomisation, on les distribue dans un des trois groupes suivants: le groupe I reçoit

\section{Key words}

ANAESTHETICS, INTRAVENOUS: etomidate, fentanyl; INTUBATION, TRACHEAL: complications.

From the Department of Anesthesiology, Box 1010, Mount Sinai Medical Center, One Gustave L. Levy Place, New York, NY 10029-6574.

Address correspondence to: Dr. David L. Reich.

Accepted for publication Ist June, 1992. du fentanyl 2,5 $\mu \mathrm{g} \cdot \mathrm{kg}^{-1}$; le groupe II, $5 \mu \mathrm{g} \cdot \mathrm{kg}^{-1}$; le groupe III, fentanyl $10 \mu \mathrm{g} \cdot \mathrm{kg}^{-1}$. Les variables hémo-dynamiques de départ sont mesurées à l'état de veille, après l'induction de l'anesthésie, à une, trois, cinq et dix minutes après l'intubation endotrachéale. Le nombre de patients qui ont montré une réponse hémodynamique à l'intubation définie comme une augmentation de $20 \%$ de la fréquence cardiaque ou de la tension artérielle moyenne, est plus élevé dans le groupe I que dans les groupes II et III. Une diminution statistiquement significative mais cliniquement sans importance de la pression artérielle moyenne et du débit cardiaque survient dans les trois groupes aux trois derniers moments d'étude. La fréquence des

mouvements musculaires involontaires est de $14 \%$ et tousces épisodes surviennent chez les patients du groupe I. En conclusion, les auteurs recommandent l'utilisation de 5 à $10 \mu \mathrm{g} \cdot \mathrm{kg}^{-1}$ pour atténuer la réponse hémodynamique à l'intuba-tion endotrachéal avec l'induction à l'étomidate $0,3 \mathrm{mg} \cdot \mathrm{kg}^{-1}$.

Etomidate (Abbott Pharm, Abbott Park, IL) is an imidazole-derivative intravenous anaesthetic induction agent remarkable for its minimal cardiovascular effects and rapid onset of action. ${ }^{1,2}$ It has, however, been associated with tachycardic and hypertensive responses to tracheal intubation. ${ }^{3}$ These haemodynamic changes may have adverse effects on the myocardial oxygen supply versus demand ratio and may result in higher incidences of perioperative ischaemia. ${ }^{4}$ Fentanyl is a highly lipophilic opioid of ten used during anaesthetic induction to attenuate the response to laryngoscopy and tracheal intubation. ${ }^{5-7}$ The ideal dose of fentanyl for the prevention of the haemodynamic response to laryngoscopy and intubation following etomidate anaesthetic induction has not yet been determined. The administration of these drugs for induction of general anaesthesia would provide rapid achievement of conditions suitable for endotracheal intubation with minimal haemodynamic response if given in appropriate doses. A population of patients presenting for 
elective myocardial revascularization was studied in order to identify how this group would respond, as these patients are in a high-risk group and are often on medications that modify cardiovascular responses.

\section{Methods}

The study protocol was approved by the Institutional Review Board and written informed consent was obtained from each patient. Thirty adult patients scheduled for elective myocardial revascularization were included in the study. Patients with left ventricular dysfunction (left ventricular ejection fraction $<40 \%$ ), atrial fibrillation, valvular heart disease, uncontrolled hypertension (diastolic BP > $100 \mathrm{mmHg}$ ), or pulmonary disease, were excluded from the study. Cardiac medications, including betaadrenergic blockers, calcium channel blockers, and nitrates, were continued until the morning of surgery. Preanaesthetic medication consisted of morphine sulphate, $0.1 \mathrm{mg} \cdot \mathrm{kg}^{-1}$, and scopolamine, $5 \mu \mathrm{g} \cdot \mathrm{kg}^{-1} \mathrm{im}$, one hour before arrival in the operating suite. Monitoring included ECG leads II and $\mathrm{V}_{5}$, and digital pulse oximetry $\left(\mathrm{SpO}_{2}\right)$. Radial arterial and rapid-response thermistor pulmonary arterial catheters were placed using local anaesthesia. After placement of the catheters, five minutes elapsed before the beginning of the study.

Assignment to three experimental groups was done using a table of random numbers. Group I received etomidate, $0.3 \mathrm{mg} \cdot \mathrm{kg}^{-1}$, and fentanyl, $2.5 \mu \mathrm{g} \cdot \mathrm{kg}^{-1}$ for anaesthetic induction. Group II received etomidate, 0.3 $\mathrm{mg} \cdot \mathrm{kg}^{-1}$ and fentanyl, $5 \mu \mathrm{g} \cdot \mathrm{kg}^{-1}$. Group III received etomidate, $0.3 \mathrm{mg} \cdot \mathrm{kg}^{-1}$, and fentanyl, $10 \mu \mathrm{g} \cdot \mathrm{kg}^{-1}$. The study was conducted in double-blind fashion, and the fentanyl dose was diluted with bacteriostatic water so that equal volumes were administered to patients in all three groups.

Awake baseline $\left(\mathrm{T}_{0}\right)$ haemodynamic values were obtained while the patients were breathing $100 \%$ oxygen via a semi-closed circle anaesthesia circuit. All medications were given through a central venous catheter. A priming dose of vecuronium, $0.015 \mathrm{mg} \cdot \mathrm{kg}^{-1}$, was administered during the completion of baseline haemodynamic measurements. The fentanyl dose was administered over $30 \mathrm{sec}$, followed immediately by the etomidate dose over $30 \mathrm{sec}$. Vecuronium, $0.085 \mathrm{mg} \cdot \mathrm{kg}^{-1}$, was administered immediately after loss of consciousness. The lungs were manually ventilated with $100 \%$ oxygen prior to tracheal intubation. Asleep baseline $\left(T_{1}\right)$ haemodynamic values were obtained starting one minute after the vecuronium dose. Tracheal intubation was performed two minutes after completion of the vecuronium dose. After proper endotracheal tube placement was confirmed, the lungs were ventilated mechanically with $100 \%$ oxygen and a tidal volume of $10 \mathrm{ml} \cdot \mathrm{kg}^{-1}$. The ventilatory rate was adjusted to maintain $\mathrm{PETCO}_{2}$ of $30-35 \mathrm{mmHg}$ using a capnometer. Patients were left unstimulated for the duration of the study period (i.e., ten minutes after intubation).

Haemodynamic variables including heart rate (HR), mean arterial pressure (MAP), mean pulmonary arterial pressure (MPAP), pulmonary capillary wedge pressure (PCWP), right atrial pressure (RAP), cardiac output (CO), right ventricular ejection fraction (RVEF), right ventricular end-systolic volume (RVESV), right ventricular enddiastolic volume (RVEDV) and stroke volume (SV) were measured at six different times:

$\mathrm{T}_{0}$ - Awake baseline, prior to anaesthetic induction with the patient breathing $100 \%$ oxygen via face mask.

$\mathrm{T}_{1}$ - One minute after anaesthetic induction, during manual ventilation, prior to tracheal intubation.

$\mathrm{T}_{2}$ - One minute after tracheal intubation (three minutes after induction).

$\mathrm{T}_{3}$ - Three minutes after tracheal intubation.

$\mathrm{T}_{4}$ - Five minutes after tracheal intubation.

$\mathrm{T}_{5}$ - Ten minutes after tracheal intubation.

Electrocardiographic and pressure tracings were recorded continously on a multi-channel recorder for subsequent analysis. All measurements were made at endexpiration. Before the inital set of measurements was made, the zero reference point of the transducers was positioned at the level of the right atrium, $5 \mathrm{~cm}$ posterior to the sternal angle of Louis. Intravenous fluid infusions were not started until arrival in the operating room, and were restricted to less than $500 \mathrm{ml}$ of a crystalloid solution prior to anaesthetic induction.

Thermodilution data were collected using a Baxter Edwards rapid-response thermistor pulmonary arterial catheter and an American Edwards REF-1 ${ }^{\circledR}$ Cardiac Output Computer (Baxter Healthcare Corp., Irvine, CA). ${ }^{8}$ Ten $\mathrm{ml}$ boluses of iced $5 \%$ dextrose solution were injected until three cardiac output values within $10 \%$ of each other were obtained. (A maximum of five bolus injections was possible within a two-minute interval.) Cardiac output and RVEF were both measured from each thermodilution curve. Three $C O$ and $R V E F$ values were averaged for each study interval, and SV, RVESV, and RVEDV were calculated by the cardiac output computer.

Hypertension and tachycardia were defined as increases of greater than $20 \%$ from the awake baseline values. Tachycardic or hypertensive episodes were treated with esmolol, $0.5 \mathrm{mg} \cdot \mathrm{kg}^{-1}$. Following the study period, the patients in all groups received an additional $50 \mu \mathrm{g} \cdot \mathrm{kg}^{-1}$ of fentanyl prior to skin incision.

Contingency data were analyzed using Fisher's exact test. Repeated-measures ANOVA and Scheffe's multiple contrasts were used to evaluate changes occurring within groups. A $P$ of less than 0.05 was considered statistically significant. All analyses were two-tailed. 


\section{Results}

Twenty-nine of 30 patients that were entered in the study went on to complete the protocol. One patient was excluded because of difficult tracheal intubation, with prolonged and repeated attempts to visualize the patient's larynx. Of the remaining 29 patients, there were nine in Group I, eight in Group II, and 12 in Group III. The groups were comparable with regard to demographic data, preoperative myocardial function, and chronic medications taken. Our sample size may have been too small to identify differences in patients taking beta blockers or calcium channel blockers. Demographic data are summarized in Table I.

The number of patients that required treatment for hypertension and/or tachycardia was 5 of 9 in Group 1, 0 of 8 in Group II, and 2 of 12 in Group III. Treatment with esmolol was required with greater frequency in Group I $(P$ $<0.05$ ) than in Groups II and III combined (Table II). In each patient that required esmolol, it was needed within one minute after intubation (between $T_{1}$ and $T_{2}$ ). Each of these patients responded promptly, and did not require further treatment for hypertension or tachycardia.There was no electrocardiographic evidence of myocardial ischaemia during the study.

The haemodynamic changes are summarized in Table III. In Group I, CO decreased at $\mathrm{T}_{1}$, and again at times $\mathrm{T}_{3}-\mathrm{T}_{5}$. A decrease in MAP was also present at $T_{5}$. In

TABLE I Demographic data $(n=29)$

\begin{tabular}{llll}
\hline & $\begin{array}{l}\text { Group I } \\
(n=9)\end{array}$ & $\begin{array}{l}\text { Group II } \\
(n=8)\end{array}$ & $\begin{array}{l}\text { Group III } \\
(n=12)\end{array}$ \\
\hline Age (mean $\pm \mathrm{SD})$ & $67.6 \pm 8.7$ & $69.5 \pm 6.2$ & $63.5 \pm 8.3$ \\
Sex ratio & $7 \mathrm{M}: 2 \mathrm{~F}$ & $7 \mathrm{M}: 1 \mathrm{~F}$ & $11 \mathrm{M}: \mathrm{IF}$ \\
Nitrates & $78 \%$ & $88 \%$ & $67 \%$ \\
Beta-blockers & $33 \%$ & $22 \%$ & $56 \%$ \\
Calcium entry blockers & $78 \%$ & $75 \%$ & $58 \%$ \\
Anti-hypertensives & $22 \%$ & 0 & $25 \%$ \\
\hline
\end{tabular}

There were no significant differences among the groups.

TABLE II Incidence of hypertension/tachycardia following tracheal intubation (number of patients)

\begin{tabular}{llll}
\hline & Fentanyl & & \\
\cline { 2 - 3 } & $\begin{array}{l}\text { Group I } \\
2.5 \mu g \cdot \mathrm{kg}^{-1}\end{array}$ & $\begin{array}{l}\text { Groups II and III } \\
5 \text { or } 10 \mu \mathrm{\mu g} \cdot \mathrm{kg}^{-1}\end{array}$ & Total \\
\hline $\begin{array}{l}\text { Hypertensive } \\
\text { tachycardic } \\
\begin{array}{l}\text { No haemodynamic } \\
\text { response }\end{array}\end{array}$ & 5 & 2 & 7 \\
Total & $\frac{4}{9}$ & $\frac{18}{20}$ & $\frac{22}{29}$ \\
\hline
\end{tabular}

$P<0.05$.
Group II, CO was decreased at $\mathrm{T}_{1}$ and $\mathrm{T}_{5}$, MAP was decreased at $T_{1}$, and $T_{3}-T_{5}$, PCWP was decreased at $T_{1}-T_{3}$, and MPAP was decreased at $T_{4}$ and $T_{5}$. In Group III, CO decreased at $T_{1}-T_{5}$, MAP was decreased at $T_{1}$, and $T_{3}-T_{5}, H R$ was decreased at $T_{4}$ and $T_{5}$, and there was an isolated increase in RAP at $T_{4}$. None of the study patients complained of pain during administration of etomidate. Four patients in Group I, and none in either of the other two groups exhibited involuntary muscle movements after the administration of etomidate. This did not represent a difference among the groups. No patient suffered any adverse sequelae attributable to the study.

\section{Discussion}

Etomidate is a rapid-acting nonbarbiturate hypnotic agent. Initially, there was reluctance to use etomidate because of the adrenocortical suppression caused by continuous infusions. ${ }^{9}$ However, subsequent work has shown that a single bolus dose of etomidate does not cause clinically important suppression of adrenocortical function, ${ }^{10}$ although there is some controversy on this. ${ }^{11,12}$ Etomidate has been shown to be devoid of adverse cardiovascular effects when used as an induction agent in patients with preexisting cardiovascular disease. ${ }^{3}$ However, it does not blunt the haemodynamic response to laryngoscopy and tracheal intubation reliably and, therefore, is not ideal as a sole agent for anaesthetic induction in patients with cardiovascular disease. ${ }^{14}$ Brief episodes of hypertension and/or tachycardia may not contribute to adverse outcomes but prolongation of these episodes most probably would.

Rapid sequence induction of general anaesthesia may precipitate undesirable haemodynamic effects. Unfortunately, there is no sole anaesthetic agent that provides haemodynamic stability during rapid sequence induction and tracheal intubation. Rapid injection of high doses of opioids is associated with chest wall rigidity. ${ }^{13}$ Barbiturates $^{14}$ and propofol ${ }^{15}$ are associated with dose-related myocardial depression and hypotension, and ketamine ${ }^{16}$ is associated with tachycardia and hypertension. The use of the etomidate/fentanyl combination may provide haemodynamic stability during both induction of anaesthesia and tracheal intubation. The aim of the current study was to determine the lowest dose of fentanyl that would blunt undesirable haemodynamic responses to laryngoscopy and tracheal intubation following anaesthetic induction with etomidate.

In the present study, 29 patients presenting for coronary artery revascularization received etomidate $0.3 \mathrm{mg} \cdot \mathrm{kg}^{-1}$ and were randomized to receive fentanyl in one of three doses. The patients who received fentanyl, $2.5 \mu \mathrm{g} \cdot \mathrm{kg}^{-1}$ (Group I), required treatment for tachycardia and/or hypertension significantly more often than patients who received fentanyl, 5 or $10 \mu \mathrm{g} \cdot \mathrm{kg}^{-1}$. Despite the high 
TABLE III Haemodynamic response to etomidate/fentanyl anaesthetic induction (means \pm SD)

\begin{tabular}{|c|c|c|c|c|c|c|}
\hline & $T_{0}$ & $T_{1}$ & $T_{2}$ & $T_{3}$ & $T_{4}$ & $T_{5}$ \\
\hline \multicolumn{7}{|l|}{ Group I } \\
\hline HR (bpm) & $62 \pm 10$ & $57 \pm 11$ & $74 \pm 18$ & $56 \pm 12$ & $57 \pm 10$ & $51 \pm 8$ \\
\hline $\mathrm{MAP}(\mathrm{mmHg})$ & $103 \pm 17$ & $89 \pm 15$ & $104 \pm 22$ & $91 \pm 18$ & $86 \pm 20$ & $83 \pm 17^{*}$ \\
\hline MPAP (mmHg) & $21 \pm 4$ & $21 \pm 4$ & $26 \pm 10$ & $23 \pm 11$ & $21 \pm 10$ & $19 \pm 7$ \\
\hline PCWP (mmHg) & $15 \pm 4$ & $13 \pm 3$ & $11 \pm 6$ & $11 \pm 6$ & $14 \pm 7$ & $15 \pm 7$ \\
\hline RAP (mmHg) & $8 \pm 3$ & $9 \pm 3$ & $11 \pm 5$ & $10 \pm 4$ & $10 \pm 3$ & $9 \pm 4$ \\
\hline $\mathrm{CO}\left(\mathrm{L} \cdot \mathrm{min}^{-1}\right)$ & $4.8 \pm 1.3$ & $4.1 \pm 0.9 \dagger$ & $4.5 \pm 1.1$ & $4.1 \pm 1.1^{*}$ & $3.9 \pm 1.1 \dagger$ & $3.7 \pm 1.0 \dagger$ \\
\hline RVEF & $0.51 \pm 0.08$ & $0.48 \pm 0.09$ & $0.48 \pm 0.10$ & $0.45 \pm 0.10$ & $0.48 \pm 0.09$ & $0.47 \pm 0.09$ \\
\hline RVEDV (ml) & $161 \pm 28$ & $152 \pm 30$ & $156 \pm 40$ & $161 \pm 52$ & $156 \pm 37$ & $150 \pm 30$ \\
\hline RVESV (ml) & $79 \pm 20$ & $79 \pm 21$ & $80 \pm 22$ & $89 \pm 39$ & $81 \pm 23$ & $79 \pm 25$ \\
\hline $\mathrm{SV}(\mathrm{ml})$ & $82 \pm 16$ & $74 \pm 19$ & $77 \pm 25$ & $72 \pm 22$ & $75 \pm 23$ & $70 \pm 17$ \\
\hline $\operatorname{SVR}\left(\mathrm{d} \cdot \mathrm{s} \cdot \mathrm{cm}^{-5}\right)$ & $1695 \pm 600$ & $1633 \pm 386$ & $1740 \pm 532$ & $1699 \pm 591$ & $1648 \pm 550$ & $1674 \pm 406$ \\
\hline PVR $\left(\mathrm{d} \cdot \mathrm{s} \cdot \mathrm{cm}^{-5}\right)$ & $114 \pm 61$ & $161 \pm 92$ & $189 \pm 110$ & $145 \pm 89$ & $143 \pm 94$ & $108 \pm 54$ \\
\hline \multicolumn{7}{|l|}{ Group II } \\
\hline HR (bpm) & $57 \pm 12$ & $50 \pm 13$ & $55 \pm 14$ & $51 \pm 10$ & $51 \pm 9$ & $48 \pm 8$ \\
\hline MAP (mmHg) & $103 \pm 18$ & $76 \pm 14 \dagger$ & $91 \pm 24$ & $85 \pm 19 *$ & $83 \pm 23^{*}$ & $81 \pm 14 \dagger$ \\
\hline MPAP (mmHg) & $21 \pm 7$ & $19 \pm 5$ & $20 \pm 7$ & $18 \pm 6$ & $18 \pm 5^{*}$ & $17 \pm 4 \dagger$ \\
\hline PCWP (mmHg) & $14 \pm 7$ & $11 \pm 6 \dagger$ & $11 \pm 5 \dagger$ & $11 \pm 5 \dagger$ & $12 \pm 6$ & $12 \pm 6$ \\
\hline RAP (mmHg) & $9 \pm 3$ & $12 \pm 5^{*}$ & $10 \pm 5$ & $10 \pm 4$ & $10 \pm 4$ & $10 \pm 5$ \\
\hline $\mathrm{CO}\left(\mathrm{L} \cdot \mathrm{min}^{-1}\right)$ & $4.6 \pm 1.1$ & $3.8 \pm 1.0^{*}$ & $4.4 \pm 1.4$ & $4.1 \pm 1.2$ & $3.8 \pm 0.8$ & $3.5 \pm 0.7 \dagger$ \\
\hline RVEF & $0.46 \pm 0.08$ & $0.47 \pm 0.08$ & $0.50 \pm 0.08$ & $0.49 \pm 0.08$ & $0.50 \pm 0.06$ & $0.48 \pm 0.08$ \\
\hline RVEDV (ml) & $184 \pm 39$ & $168 \pm 47$ & $154 \pm 35$ & $164 \pm 29$ & $149 \pm 15$ & $155 \pm 22$ \\
\hline RVESV (ml) & $101 \pm 29$ & $91 \pm 36$ & $80 \pm 29$ & $86 \pm 24$ & $75 \pm 15$ & $82 \pm 22$ \\
\hline $\mathrm{SV}(\mathrm{ml})$ & $81 \pm 17$ & $77 \pm 15$ & $75 \pm 13$ & $78 \pm 9$ & $73 \pm 8$ & $73 \pm 6$ \\
\hline $\operatorname{SVR}\left(\mathrm{d} \cdot \mathrm{s} \cdot \mathrm{cm}^{-5}\right)$ & $1690 \pm 393$ & $1448 \pm 493$ & $1558 \pm 652$ & $1545 \pm 568$ & $1554 \pm 535$ & $1655 \pm 384$ \\
\hline $\operatorname{PVR}\left(\mathrm{d} \cdot \mathrm{s} \cdot \mathrm{cm}^{-5}\right)$ & $92 \pm 40$ & $138 \pm 68$ & $119 \pm 55$ & $109 \pm 48$ & $82 \pm 33$ & $88 \pm 25$ \\
\hline \multicolumn{7}{|l|}{ Group III } \\
\hline HR (bpm) & $63 \pm 18$ & $56 \pm 15$ & $69 \pm 19$ & $59 \pm 12$ & $54 \pm 14 \dagger$ & $53 \pm 15 \dagger$ \\
\hline MAP (mmHg) & $98 \pm 10$ & $76 \pm 10 \dagger$ & $93 \pm 20$ & $81 \pm 15 \dagger$ & $80 \pm 16 \dagger$ & $81 \pm 16 \dagger$ \\
\hline MPAP (mmHg) & $21 \pm 5$ & $19 \pm 4$ & $22 \pm 10$ & $20 \pm 7$ & $19 \pm 7$ & $19 \pm 5$ \\
\hline PCWP (mmHg) & $15 \pm 4$ & $13 \pm 3$ & $14 \pm 5$ & $14 \pm 7$ & $15 \pm 7$ & $13 \pm 2$ \\
\hline RAP (mmHg) & $8 \pm 2$ & $11 \pm 2$ & $10 \pm 3$ & $10 \pm 3$ & $12 \pm 7 \dagger$ & $10 \pm 3$ \\
\hline $\mathrm{CO}\left(\mathrm{L} \cdot \mathrm{min}^{-1}\right)$ & $5.3 \pm 1.5$ & $4.4 \pm 1.5 \dagger$ & $4.4 \pm 1.5 \dagger$ & $4.3 \pm 1.3 \dagger$ & $3.9 \pm 1.3 \dagger$ & $4.1 \pm 1.3 \dagger$ \\
\hline RVEF & $0.52 \pm 0.09$ & $0.52 \pm 0.07$ & $0.53 \pm 0.11$ & $0.52 \pm 0.09$ & $0.50 \pm 0.07$ & $0.50 \pm 0.09$ \\
\hline RVEDV (ml) & $151 \pm 45$ & $141 \pm 41$ & $133 \pm 43$ & $138 \pm 38$ & $137 \pm 42$ & $151 \pm 49$ \\
\hline RVESV (ml) & $72 \pm 25$ & $70 \pm 25$ & $64 \pm 29$ & $68 \pm 24$ & $68 \pm 24$ & $76 \pm 31$ \\
\hline$S V(m l)$ & $78 \pm 22$ & $71 \pm 20$ & $68 \pm 21$ & $70 \pm 20$ & $69 \pm 21$ & $75 \pm 22$ \\
\hline $\operatorname{SVR}\left(\mathrm{d} \cdot \mathrm{s} \cdot \mathrm{cm}^{-5}\right)$ & $1526 \pm 764$ & $1332 \pm 602$ & $1687 \pm 817$ & $1434 \pm 593$ & $1549 \pm 662$ & $1511 \pm 618$ \\
\hline PVR $\left(\mathrm{d}: \mathrm{s} \cdot \mathrm{cm}^{-5}\right)$ & $114 \pm 85$ & $115 \pm 62$ & $146 \pm 98$ & $122 \pm 53$ & $100 \pm 59$ & $106 \pm 38$ \\
\hline
\end{tabular}

* $P<0.05$ compared with $\mathrm{T}_{0}, \dagger P<0.01$ compared with $\mathrm{T}_{0}$ (within-group comparisons).

$(\mathrm{HR}=$ heart rate, $\mathrm{MAP}=$ mean arterial pressure, $\mathrm{MPAP}=$ mean pulmonary artery pressure, $\mathrm{PCWP}=$ pulmonary capillary wedge pressure, $\mathrm{RAP}=$ right atrial pressure, $\mathrm{CO}=$ cardiac output, $\mathrm{RVEF}=$ right ventricular ejection fraction, $\mathrm{RVEDV}=$ right ventricular end diastolic volume, $\mathrm{RVESV}=$ right ventricular end systolic volume, $\mathrm{SV}=$ stroke volume, $\mathrm{SVR}=$ systemic vascular resistance, $\mathrm{PVR}=$ pulmonary vascular resistance.)

incidence of tachycardia and/or hypertension (five of nine patients) in Group I during tracheal intubation, the statistical analysis did not detect any increases in haemodynamic variables. This was because the patients were treated as soon as the HR or MAP increased to greater than $20 \%$ above baseline values. In each case, effective treatment had been instituted before the first post-intubation study measurement time.

There were decreases in MAP and $\mathrm{CO}$ in all three treatment groups ten minutes after tracheal intubation.
These findings are consistent with the unstimulated, anaesthetized state and were not clinically significant. The changes in PCWP $\left(\mathrm{T}_{1}-\mathrm{T}_{3}\right)$ and MPAP $\left(\mathrm{T}_{4}-\mathrm{T}_{5}\right)$ in Group II, and in HR $\left(\mathrm{T}_{4}-\mathrm{T}_{5}\right)$ and RAP $\left(\mathrm{T}_{4}\right)$ in Group III were not clinically important. All of these values remained within acceptable limits in individual patients and did not require therapeutic intervention. Our results likely would have been altered by the adminstration of other drugs as premedications and therefore we do not recommend extrapolation of our data to patients given other premedications. 
Two unpleasant side affects of etomidate are pain during injection and involuntary muscle movements. ${ }^{17,18}$ We administered all drugs via a central venous line, and did not encounter any patient discomfort. The frequency of involuntary muscle movements was $14 \%$. The reported frequency of involuntary muscle movements with etomidate as the sole induction agent is $15-53 \% .17,19$ Pretreatment with an opioid reportedly decreases this frequency, ${ }^{20}$ which is consistent with our findings. None of the patients in groups II or III experienced involuntary muscle movements.

In previous studies, there have been variable and conflicting results with the use of etomidate and fentanyl combinations to prevent the haemodynamic changes that accompany tracheal intubation. In one study, fentanyl, 100 $\mu \mathrm{g}$, was administered during anaesthetic induction with etomidate, $0.4 \mathrm{mg} \cdot \mathrm{kg}^{-1}$. ${ }^{21}$ The patients in that study had increases in heart rate and blood pressure after trachea? intubation. This study differs from the present one in that the patients were healthy (ASA physical status I or II), atropine was used as preanaesthetic medication, and that succinylcholine was used to facilitate tracheal intubation. In another study, patients were given fentanyl, 100-150 $\mu \mathrm{g}$, during anaesthetic induction with etomidate, 0.3 $\mathrm{mg} \cdot \mathrm{kg}^{-1} \cdot{ }^{22}$ In those patients, anaesthetic induction and tracheal intubation did not alter haemodynamic values. However, the emergency coronary angioplasty patients in that study had all received lidocaine $(225 \mathrm{mg}$ iv bolus followed by $2 \mathrm{mg} \cdot \mathrm{min}^{-1}$ ) which probably further blunted the haemodynamic response to intubation.

The present study differed from that of Inoue $e t$ al., who found decreases in heart rate when etomidate, $0.3 \mathrm{mg} \cdot \mathrm{kg}^{-1}$, and vecuronium (with or without fentanyl, $3 \mu \mathrm{g} \cdot \mathrm{kg}^{-1}$ ), were used for anaesthetic induction. ${ }^{23}$ In their series, five out of 30 patients receiving this combination of drugs required atropine treatment for heart rates below 45 beats per minute. The bradycardic responses may have been due to the timing of drug administration. They waited two minutes after the administration of fentanyl before injecting the etomidate and vecuronium, whereas, in the current study, the drugs were all injected within $60 \mathrm{sec}$. In addition, their study sample may have had a higher incidence of sinus node dysfunction.

Karliczek $e t$ al., studied the effect of two doses of fentanyl in combination with etomidate infusions. ${ }^{19}$ They found tachycardia and hypertension following $3 \mu \mathrm{g} \cdot \mathrm{kg}^{-1}$ of fentanyl. However, the $6 \mu \mathrm{g} \cdot \mathrm{kg}^{-1}$ dose of fentanyl was associated with hypotension. Their results do not agree with those of the current study, but this may have been due to higher etomidate levels achieved by constant infusions of etomidate.

The present study does have several limitations. Firstly, collecting three consistent sets of haemodynamic variables using the right ventricular ejection fraction pulmonary artery catheter took approximately $90 \mathrm{sec}$ to complete. Thus, any transient changes in $\mathrm{CO}, \mathrm{SV}$, or SVR may have been missed. Secondly, our patients were let untouched for ten minutes after intubation. We did not allow any stimulation because we were attempting to measure the haemodynamic response to tracheal intubation alone. Thirdly, the patients in the study were premedicated with morphine and scopolamine. The heavy preanaesthetic medication could have influenced the haemodynamic responses. The last two issues make it more difficult to extrapolate these data to patients with coronary artery disease presenting for surgical procedures of shorter duration.

In conclusion, none of the previous studies ${ }^{17-20,23}$ established a dose-response relationship between boluses of etomidate and fentanyl, and none of these investigators administered the agents in a way that would be appropriate for a rapid-sequence induction. The purpose of the current investigation was to establish the doses of etomidate and fentanyl that would provide haemodynamic stability during anaesthetic induction and tracheal intubation. The authors recommend that fentanyl, $5-10 \mu \mathrm{g} \cdot \mathrm{kg}^{-1}$, be administered $60 \mathrm{sec}$ before anaesthetic induction with etomidate, $0.3 \mathrm{mg} \cdot \mathrm{kg}^{-1}$, when tachycardia and hypertension are undesirable. Further investigations are needed to confirm that these doses of etomidate and fentanyl provide haemodynamic stability during rapid-sequence inductions, and in patients with ventricular dysfunction.

\section{Acknowledgements}

The authors gratefully acknowledge Abbott Laboratories, Inc. for providing etomidate, and James B. Eisenkraft, M.D. for a critical review of the manuscript. In addition, the cooperation of the cardiothoracic operating room and technical staff was greatly appreciated.

\section{References}

1 Giese JL, Stanley TH. Etomidate: a new intravenous anesthetic induction agent. Pharmacotherapy $1983 ; 3: 251-8$.

2 White $P F$. Clinical pharmacology of intravenous induction drugs. Int Anesthesiol Clin 1988; 26: 98-104.

3 Gooding JM, Weng JT, Smith RA, Beringer GT, Kirby RR. Cardiovascular and pulmonary responses following etomidate induction of anesthesia in patients with demonstrated cardiac disease. Anesth Analg 1979; 58: 40-1.

4 Slogoff $S$, Keats $A S$. Does chronic treatment with calcium entry blocking drugs reduce perioperative myocardial ischemia? Anesthesiology 1988; 68: 676-80.

5 Moffitt EA, McIntyre AJ, Barker RA, et al. Myocardial metabolism and hemodynamic responses with fentanylenflurane anesthesia for coronary arterial surgery. Anesth Analg 1986; 65: 46-52.

6 Martin DE, Rosenberg H, Aukburg SJ, et al. Low-dose 
fentanyl blunts circulatory responses to tracheal intubation. Anesth Analg 1982; 61: 680-4.

7 Splinter WM, Cervenko F. Haemodynamic responses to laryngoscopy and tracheal intubation in geriatric patients: effects of fentanyl, lidocaine and thiopentone. Can J Anaesth 1989; 36: 370-6.

8 Dhainaut J-F, Brunet F, Monsallier JF, et al. Bedside evaluation of right ventricular performance using a rapid computerized thermodilution method. Crit Care Med 1987; 15: 148-52.

9 Fellows IW, Bastow MD, Byrne AJ, Allison SP. Adrenocortical suppression in multiply injured patients: a complication of etomidate treatment. BMJ 1983; 287 : 1835-7.

10 Duthie D, Fraser R, Nimmo W. Effect of induction of anaesthesia with etomidate on corticosteroid synthesis in man. Br J Anaesth 1985; 57: 156-9.

11 Kenyon CJ, McNeil LM, Fraser R. Comparison of the effects of etomidate, thiopentone and propofol on cortisol synthesis. Br J Anaesth 1985; 57: 509-11.

12 Lambert A, Mitchell R, Robertson WR. Effect of propofol, thiopentone and etomidate on adrenal steroidogenesis in vitro. Br J Anaesth 1985; 57: 505-8.

13 Stoelting RK, Gibbs PS, Creasser CW, Peterson C. Hemodynamic and ventilatory responses to fentanyl, fentanyldroperidol, and nitrous oxide in patients with acquired valvular heart disease. Anesthesiology 1975; 42: 319-24.

14 Frankl WS, Poole-Wilson PA. Effects of thiopental on tension development, action potential, and exchange of calcium and potassium in rabbit ventricular myocardium. $\mathbf{J}$ Cardiovasc Pharmacol 1981; 3: 554-65.

15 Stephan H, Sonntag H, Schenk HD, Kettler D, Khambatta $H J$. Effects of propofol on cardiovascular dynamics, myocardial blood flow and myocardial metabolism in patients with coronary artery disease. Br J Anaesth 1986; 58 : 969-75.

16 White $P F$, Way WL, Trevor AJ. Ketamine-its pharmacology and therapeutic uses. Anesthesiology 1982; 56: 119-36.

17 Korttila K, Tammisto T, Aromaa U. Comparison of etomidate in combination with fentanyl or diazepam, with thiopentone as an induction agent for general anesthesia. $\mathrm{Br} \mathrm{J}$ Anaesth 1979; 51: 1151-7.

18 Carlos $R$, Innerarity $S$. Effect of premedication on etomidate anaesthesia. Br J Anaesth 1979; 51: 1159-62.

19 Karliczek GF, Bremken $U$, Schokkinbroek $R$, van der Broeke JJ, Richardson FJ, van der Heide JN. Etomidate analgesic combinations for the induction of anaesthesia in cardiac patients. Part I: Studies in patients with coronary artery disease. Anaesthesist 1982; 31: 51-60.

20 Zacharias $M$, Dundee JW, Clark RS, Hegarty JE. Effects of preanesthetic medication on etomidate. $\mathrm{Br} J$ Anaesth 1979; 51: 127-33.
21 Giese JL, Stockham RJ, Stanley TH, Pace NL, Nelissen $R H$. Etomidate versus thiopental for induction of anesthesia. Anesth Analg 1985; 64: 871-6.

22 Kates RA, Stack RS, Hill RF, et al. General anesthesia for patients undergoing percutaneous transluminal coronary angioplasty during acute myocardial infarction. Anesth Analg 1986; 65: 815-8.

23 Inoue K, El-Banayosy A, Stolarski L, Reichelt W. Vecuronium induced bradycardia following induction of anaesthesia with etomidate or thiopentone, with or without fentanyl. Br J Anaesth 1988; 60: 10-7. 